\title{
Isolated soya protein with standardised levels of isoflavones, cotyledon soya fibres and soya phospholipids improves plasma lipids in hypercholesterolaemia: a double-blind, placebo-controlled trial of a yoghurt formulation
}

\author{
Pekka Puska $^{1 \star}$, Vesa Korpelainen ${ }^{2}$, Lars H. Høie ${ }^{3}$, Eva Skovlund ${ }^{4}$ and Knut T. Smerud ${ }^{5}$ \\ ${ }^{1}$ National Public Health Institute, Mannerheimintie 166, FIN-00300 Helsinki, Finland \\ ${ }^{2}$ North Karelia Project, Joensuu, Finland \\ ${ }^{3}$ Nutri Pharma A/S, Copenhagen, Denmark \\ ${ }^{4}$ Section of Medical Statistics, University of Oslo, Oslo, Norway \\ ${ }^{5}$ Smerud Medical Research International AS, Oslo, Norway
}

(Received 17 April 2003 - Revised 23 October 2003 - Accepted 12 November 2003)

\begin{abstract}
The objective was to study whether a yoghurt containing isolated soya protein with standardised levels of isoflavones, cotyledon soya fibres and soya phospholipids is more effective in lowering total and LDL-cholesterol than a placebo. One hundred and forty-three subjects were randomised to the soya group $(n 69)$ or to the placebo $(n 74)$. The mean baseline levels were 7.6 and $5 \cdot 1 \mathrm{mmol} / \mathrm{l}$ for total and LDL-cholesterol, respectively. Fasting serum lipoproteins were assessed five times during the 8 -week intervention period, and 4 weeks thereafter. The results were analysed by a mixed model for unbalanced repeated measurements. During the intervention, there were highly significant differences in lipid-lowering effect in favour of the active soya intervention group compared with the control group. The significant differences were for total cholesterol (estimated mean difference $0.40 \mathrm{mmol} / \mathrm{l} ; P<0.001)$, LDL-cholesterol (0.39 mmol/1; $P<0.001$ ), non-HDLcholesterol $(0.40 \mathrm{mmol} / \mathrm{l} ; P<0.001)$ and for the total:HDL-cholesterol ratio $(0.23 ; P=0.005)$. There was no difference in the effects on HDL-cholesterol, triacylglycerols or homocysteine. The lipid-lowering effect occurred within 1-2 weeks of intervention, and was not due to weight loss. The safety profile for active soya was similar to the placebo group, except for gastrointestinal symptoms, which caused a significantly higher dropout rate (fourteen $v$. three subjects) among the subjects taking active soya.
\end{abstract}

Soya protein: Fibre: Isoflavones: Phospholipids: Hypercholesterolaemia

It is well established through epidemiological research that hypercholesterolaemia is among the major causes for CHD and that changes in diet may influence this and other risk factors for such disease (Pietinen et al. 1996; Grundy, 2000; Stamler et al. 2000; Vartiainen et al. 1994). Several large, prospective intervention studies using statins have further demonstrated that reducing the cholesterol level also reduces the risk of cardiovascular morbidity and mortality (The Scandinavian Simvastatin Survival Study Group, 1994; Shepherd et al. 1995; The Long Term Intervention with Pravastatin in Ischemic Disease (LIPID) Study Group, 1998; Heart Protection Study Collaborative Group, 2002).

A public health approach to primary prevention of $\mathrm{CHD}$ is to call for lifestyle changes; for example, a reduced intake of cholesterol and saturated fat, exercising, weight control and smoking cessation (Anonymous, 2002). There is still some debate whether or when drug intervention is indicated for primary prevention, partly because of cost considerations and partly because of concerns over the safety of lipid-lowering drugs. Reports from the UK indicate that patient and primary-care compliance with public recommendations are not followed entirely (Anonymous, 1998; Monkman, 2000; Primatesta \& Poulter, 2000). As with other patient groups, hypercholesterolaemic patients also may be incapable of modifying their lifestyle significantly, they may be unable to comply with statin treatment (Avorn et al. 1998), or they may simply not want intervention with drugs. Various dietary supplements and functional foods have thus recently been introduced as alternatives to pharmaceuticals. In our view, before being acknowledged in clinical practice, such products should have their efficacy and tolerability documented by welldesigned, prospective, randomised, double-blind and rigorously monitored clinical trials.

The lipid-lowering efficacy of soya protein is supported by the fact that the US Food and Drug Administration (1999) has approved a health claim for products giving 
a daily dose of soya protein of at least $25 \mathrm{~g}$. A pertaining problem with clinical studies of soya proteins has been that the variability of products has been huge, as each soya-based product may have different soya components, either isolated or not. In particular, using alcohol extractions for isolating the soya protein will also remove isoflavones, components that due to their oestrogenic or anti-oestrogenic effects very well may affect serum lipid levels. A recent meta-analysis (Anderson et al. 1995) reviewed several controlled studies and concluded that the dietary substitution of soya protein for animal protein might decrease the risk of cardiovascular disease by decreasing serum cholesterol, LDL-cholesterol and triacylglycerol concentrations, and by slightly increasing serum HDL-cholesterol levels.

The active components of soya have not yet been fully elucidated. It has been suggested (Anderson, 2003) that soya protein, peptides and isoflavones may work together to produce effects on lipid metabolism and gene expression. Several potential mechanisms of action have been suggested including an influence on the endocrine system, on the intestinal absorption of bile acids and dietary cholesterol, or on the hepatic metabolism of cholesterol and/or lipoproteins (Potter, 1998) and a more specific endocrine influence of soya protein on the insulin:glucagon ratios (Anderson et al. 1999). Soya peptides, most probably from the 7S $\alpha$-fraction of the globulins (Lovati et al. 2000), are supposed to activate hepatic LDL receptors, and they appear to increase the mRNA expression of LDL receptors in circulating human monocytes (Baum et al. 1998).

Isoflavones have structures similar to mammalian oestrogens and they are capable of binding to oestrogen receptors. Depending on the hormonal status of the individual they seem to exhibit either oestrogenic or anti-oestrogenic effects. Therefore it has been postulated that premenopausally isoflavones may act anti-oestrogenic, whereas they could act post-menopausally as oestrogen receptor agonists. It is known that mammalian oestrogens can modulate the blood lipid profile, promoting decreases in LDL-cholesterol and increases in HDL-cholesterol. Oestradiol also shows potent cardioprotective effects on blood vessels (Potter, 1998). Isoflavones alone will not decrease blood lipid levels as described, but they influence the ability of soya protein preparations to reduce serum lipid concentrations.

Anderson et al. (1999) proposed several other mechanisms by which soya fibres could influence fasting and postprandial serum lipid protein concentrations. Due to the alteration of gastric emptying and intestinal transit time, dietary fibres could alter the kinetics of lipid absorption. Dietary fibre may decrease lipid absorption by modifying pancreatic secretion, the variation of intestinal motility, or by changing transport barriers such as the unstirred layer. Dietary fibre may affect the secretion rates of insulin or other pancreatic or intestinal hormones, which will change lipid and lipoprotein synthesis and secretion rates. Another suggested mechanism is that the soluble fibre of soya beans is fermented in the colon and generates SCFA such as acetate, butyrate or propionate, which inhibit hepatic lipid synthesis (Nishina \& Freedland, 1990).

Phospholipids from soya beans may protect against atherosclerosis development (Navder et al. 2000). The most obvious action of unsaturated lecithin is the protection of LDL against oxidation and peroxidation. Oxidised LDL are involved in the development of atherosclerotic lesions. Peroxidation of LDL-lipids could damage apo B-100, the surface protein of LDL and VLDL. This may increase atherogenicity, because normal catabolism through the regulated LDL receptor pathway is blocked. This results in an enhanced cholesterol uptake via an unregulated scavenger pathway, which leads to the cholesterol overloading of macrophages and the development of foam cells, a key component of atherosclerotic plaques. One major mechanism of phospholipids or soyabean lecithin is the activation of reverse cholesterol transport. This includes the activation of lecithin-cholesterol-acetyltransferase, increased cholesterol uptake by HDL and leads to an increased biliary excretion of cholesterol (Rosseneu et al. 1979; Ishida et al. 1988; Hsia et al. 1996; Polichetti et al. 1996, 2000; LeBlanc et al. 1998).

Abacor ${ }^{\circledR}$ is a new product based on isolated soya protein and cotyledon soya fibres containing standardised levels of isoflavones as well as soya phospholipids. Initial studies in subjects with mild-to-moderate hypercholesterolaemia have demonstrated that this product is efficient in lowering cholesterol (Puska et al. 2002; Tonstad et al. 2002). These early results were obtained by administering the soya product in a powder formulation to be mixed with water before intake. The aim of the present study was to demonstrate similar lipid-lowering effects with this active soya product when administered in a yoghurt formulation.

\section{Methods}

\section{Subjects}

Subjects were screened from the patient database of the Joensuu Health Centre area in North Karelia, Finland. Eligible subjects had to meet selection criteria including: written informed consent; total serum cholesterol concentration of $6.7-9.9 \mathrm{mmol} / \mathrm{l}$; serum triacylglycerols of $<4.5 \mathrm{mmol} / \mathrm{l}$; age $18-75$ years for men and $45-70$ years for post-menopausal women (at least 6 months with no vaginal bleeding after menopause). Subjects were to have no significant signs of cardiovascular, renal, hepatic, endocrine or gastrointestinal disease; no familial hypercholesterolaemia; no type I or II diabetes mellitus treated with insulin; no past or concomitant use of statins, $n$-3-fatty acids or other lipid-lowering drugs (including any cholesterol-lowering functional foods) during the last 8 weeks before randomisation. They were to have had no hormone replacement therapy within the past 6 months; have no drug or alcohol dependency; no eating disorder; and no plans to lose weight during the study.

\section{Study design and laboratory analyses}

Subjects with hypercholesterolaemia were informed about the study and invited to participate. After having given their informed consent to participate in the study, the subjects were followed for 8 weeks in an open, run-in dietary phase. During this time all subjects were asked to consume a cholesterol-lowering diet in order to reduce the variability of their baseline lipid values as recommended 
by The Swedish Medical Product Agency and the Norwegian Medicines Control Agency (1996). Their guidance is similar to the American Heart Association step I cholesterol-lowering diet (Anonymous, 2002) which recommends that the energy intake from fat should not exceed $30 \%$ of the total energy. After a baseline medical assessment, subjects who met the selection criteria were randomised to one of the two study groups. They were advised to take one yoghurt serving twice daily for the next 8 weeks as part of their normal morning and evening meal. It was attempted to keep the energy intake as constant as possible by advising the subjects to reduce their morning and evening meal with approximately the same amount of energy as they received through the study products. All subjects were seen in the clinic at week $0,2,4,6$ and 8 for compliance control (deemed by counting returned and unused containers) and blood sampling for lipid measurements. The subjects then had a final follow-up assessment after another 4 weeks without administration of any study treatment.

Fasting blood samples were taken, after 5 min supine rest, during each visit for measurement of the efficacy lipid variables. Total cholesterol, HDL-cholesterol and triacylglycerols were analysed for every visit, whereas homocysteine was measured at baseline and at the end of therapy. Blood tests for safety haematology and biochemistry (alanine aminotransferase, aspartate aminotransferase, creatinine, glucose and uric acid) as well as a brief physical examination including the control of blood pressure and heart rate were taken only at baseline and at the end of treatment. All lipids were analysed at the Department of Biochemistry at the National Public Health Institute, Helsinki, Finland. The concentrations of LDL-cholesterol were calculated according to the Friedewald et al. (1972) method. As soya products contain high levels of the isoflavones genistein and daidzein (Adlercreutz, 1998), plasma concentrations were measured by fluoroimmunoassay (Wang et al. 2000) after 8 weeks treatment as an objective measure of treatment compliance. Weight was measured at each visit, but there was no detailed diary recording in order to control energy intake. Tolerability was assessed by recording spontaneously reported adverse events, as well as by actively asking an open, non-leading question to the patient during every visit whether they had experienced any undesirable medical event since their last clinic visit.

\section{Study product}

The subjects were asked to take one cup per twice-a-day serving, both morning and afternoon, giving a daily dose of soya protein of $41.4 \mathrm{~g}$ for the Abacor ${ }^{\circledR}$ group. The active Abacor ${ }^{\circledR}$ yoghurt (the active soya treatment) was manufactured by Protein Technology International Inc., St Louis, MO, USA (soya protein and fibres) and Lucas Meyer, Hamburg, Germany (soya lecithin), whereas the placebo yoghurt was the commercially available product 'Lett Yoghurt Naturell', manufactured by Tine Sør, Kristiansand, Norway. The products were matched to each other in terms of taste, appearance, smell and flavour by adding cherry jam. The finished products were manufactured and quality controlled by the Agricultural University of Norway, As, Norway. The study products were presented in identical, unmarked (except for subject number) containers. A detailed comparison of the contents of each study treatment is presented in Table 1.

\section{Statistical analysis}

This was a randomised, placebo-controlled, double-blind, parallel-group, single-centre study. It was estimated that with approximately seventy patients in each group, the power to detect a $10 \%$ difference in LDL-cholesterol between the two study groups would be at least $90 \%$ with a $5 \%$ significance level (two-sided). Neither the investigators nor the patients knew the computer-generated randomisation code, block size or the results of the blood lipid concentrations until after the statistical analysis. Statistical analyses were conducted before breaking the randomisation code.

The primary analysis was undertaken on a modified intention-to-treat population, defined as those subjects who received the study treatment for at least 2 weeks. Changes in serum lipids over time were analysed by a mixed model for unbalanced repeated measurements employing the SAS $^{\circledR} 6.12$ software (SAS Institute, Cary, NC, USA). Parameters were estimated by the method of restricted maximum likelihood, and an unstructured covariance matrix was applied. The model included time and treatment group as the main effects and in addition the interaction between treatment and time. When no statistically significant interaction was found, the interaction term was excluded from the model. The last measurement before the start of treatment was included as a covariate in the model. Total cholesterol, HDL-cholesterol, non-HDL-cholesterol, LDL-cholesterol, LDL:HDL ratio, total:HDL-cholesterol ratio and triacylglycerols were analysed separately. Analysis of covariance was used to estimate the effect of treatment on homocysteine. The active soya treatment and placebo were compared for a total of eight efficacy variables.

In order to assess the robustness of the results, we conducted secondary analyses. In the intention-to-treat population, missing values were substituted according to the last-observation-carried-forward method. In addition, the per-protocol population consisting of study completers only (i.e. fifty-three subjects in the active soya group and seventy in the placebo group) was analysed. Both secondary analyses demonstrated that the data obtained in our primary analysis were robust and consistent.

Table 1. Contents of the yoghurt products

\begin{tabular}{lcc}
\hline & Active soya & Placebo \\
\hline Energy (kJ) & 1484 & 994 \\
Protein (g) & & \\
$\quad$ Isolated soya protein & & \\
$\quad$ Milk protein & 0.7 & 0 \\
Total fibre (g) & 4.5 & 12.2 \\
Fat (g) & 2.84 & 0 \\
Soya lecithin (g) & 1.76 & 0 \\
\hline
\end{tabular}

${ }^{*}$ Standardised as $3.7 \mathrm{mg}$ isoflavones $/ \mathrm{g}$ soya protein. 


\section{Ethics and administration}

The study protocol and informed consent form were approved by the ethics committee of the Joensuu Health Centre, Joensuu, Finland. An independent contract research organisation (Smerud Medical Research International AS, Oslo, Norway) was responsible for monitoring the study according to the International Conference on Harmonization guidelines on good clinical practice principles (European Agency for the Evaluation of Medicinal Products, 1996) and for overall quality assurance.

\section{Results}

A total of 146 subjects were admitted for the screening of selection criteria, and were subsequently randomised to receive the study products. Three subjects withdrew their consent either before or immediately after taking the first dose. Hence 143 subjects, sixty-nine in the active soya group and seventy-four in the placebo group, have been included in the analysis of efficacy. Fig. 1 shows the flow of participants through each stage of the study. The two groups were well matched at baseline (Table 2) for sex, age, body weight, BMI, blood pressure, heart rate as well as for cigarette smoking and alcohol use.

A significant proportion of patients dropped out from the study during the intervention period, as they did not tolerate the product. The difference between the study groups was statistically significant $(P=0.03)$ as fourteen subjects $(20.3 \%)$ from the active soya group, and three $(4.1 \%)$ from the placebo group dropped out, respectively. The reason for withdrawal was either 'refusal to take more study product' or 'adverse events'. The subjects complained about nausea, vomiting, stomach pain and a feeling of stomach swelling, but these symptoms were usually mild and transient. Furthermore, three of the subjects in the active soya group who refused to continue taking the study product did so after a contamination (mould growth) was found in their yoghurt cups. There were no significant changes in any of the haematological or biochemical laboratory variables.

\section{Lipid variables}

Table 3 shows the mean screening and baseline concentrations for the lipid efficacy variables. Our statistical model incorporated the results from all biweekly visits, and the mean changes from baseline as well as the estimated difference in reductions, are also presented. The difference between the active soya treatment and the placebo was statistically significant for total cholesterol-, LDL-cholesterol-, and non-HDL-cholesterol-lowering and for the total:HDL-cholesterol and LDL:HDL-cholesterol ratios, whereas no differences for HDL-cholesterol changes, or for triacylglycerols or homocysteine were found. The serum concentrations over time for total cholesterol and LDL-cholesterol are presented in Fig. 2. The reduction occurred rapidly, within 1-2 weeks, and continued up to 8 weeks. Upon withdrawal after 8 weeks of the study products, serum concentrations for both groups returned to their baseline values.

\section{Isoflavone levels}

After therapy, the genistein levels were 762.1 (SD $1001.9) \mathrm{nmol} / \mathrm{l}$ in the active soya group and 7.8 (SD $11.7) \mathrm{nmol} / \mathrm{l}$ in the placebo group. For daidzein, the aftertherapy levels were 127.0 (SD 120.5) and 2.6 (SD $5 \cdot 1) \mathrm{nmol} / \mathrm{l}$, for the active soya and placebo groups, respectively. These results confirmed that genistein and daidzein were indeed good means to distinguish those patients being reasonably compliant with taking study products and those who were not.

\section{Haemodynamics}

There were no significant changes in blood pressure or heart rate (data not shown) for either group during the study. The active soya group had systolic blood pressure of 130.0 (SD 15.8) $\mathrm{mmHg}$ at screening, 129.6 (SD 15.8) $\mathrm{mmHg}$ after the 8-week intervention, and 129.9 (SD 14.2) $\mathrm{mmHg}$ at 4 weeks after the study. However the results in the placebo group were 132.4 (SD 17.1) $\mathrm{mmHg}$ at screening, 131.3 (SD 15.7) $\mathrm{mmHg}$ after 8 weeks intervention, and 132.1 (SD 19.1) $\mathrm{mmHg}$ at 4 weeks after the intervention. For diastolic blood pressure, the findings were 80.5 (SD 8.7) $\mathrm{mmHg}$ at screening, 80.6 (SD 8.2) $\mathrm{mmHg}$ after

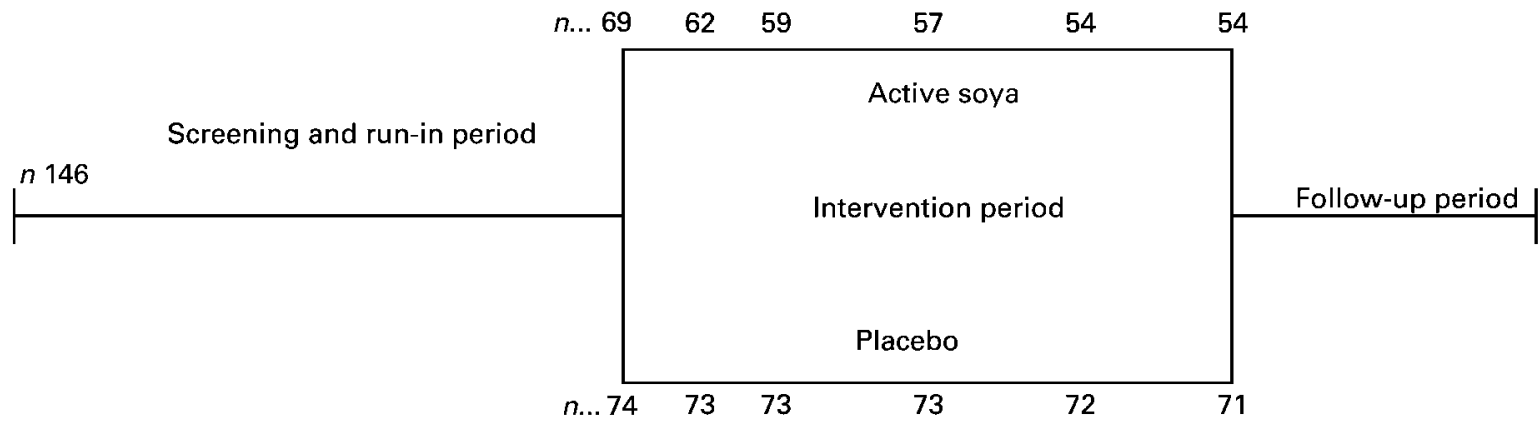

Week...-8

$\begin{array}{lll}0 & 1 & 2\end{array}$

4

6

8

Fig. 1. Study flow-chart and number of subjects at each study stage. 
Table 2. Subject characteristics at baseline (Mean values and standard deviations)

\begin{tabular}{|c|c|c|c|c|}
\hline & \multicolumn{2}{|c|}{ Active soya } & \multicolumn{2}{|c|}{ Placebo } \\
\hline & Mean & SD & Mean & SD \\
\hline \multicolumn{5}{|l|}{ Patients $(n)$} \\
\hline Total & \multicolumn{2}{|r|}{69} & \multicolumn{2}{|c|}{74} \\
\hline Males & \multicolumn{2}{|r|}{33} & \multicolumn{2}{|r|}{34} \\
\hline Females & \multicolumn{2}{|r|}{36} & \multicolumn{2}{|c|}{40} \\
\hline \multicolumn{5}{|l|}{ Age } \\
\hline Range (years) & \multirow{2}{*}{\multicolumn{2}{|c|}{$\begin{array}{r}30-70 \\
58\end{array}$}} & \multicolumn{2}{|r|}{$35-70$} \\
\hline Median (years) & & & & 58 \\
\hline \multicolumn{5}{|l|}{ Weight $(\mathrm{kg})$} \\
\hline Males & $82 \cdot 2$ & $9 \cdot 0$ & 84.5 & $10 \cdot 8$ \\
\hline Females & $72 \cdot 7$ & $15 \cdot 3$ & 68.7 & $12 \cdot 8$ \\
\hline \multicolumn{5}{|l|}{ BMI $\left(\mathrm{kg} / \mathrm{m}^{2}\right)$} \\
\hline Males & $26 \cdot 6$ & $2 \cdot 9$ & $27 \cdot 1$ & $3 \cdot 7$ \\
\hline Females & $28 \cdot 1$ & $5 \cdot 3$ & $26 \cdot 4$ & $5 \cdot 0$ \\
\hline $\begin{array}{l}\text { Systolic blood } \\
\text { pressure }(\mathrm{mmHg})\end{array}$ & $130 \cdot 0$ & $15 \cdot 8$ & $132 \cdot 4$ & $17 \cdot 1$ \\
\hline $\begin{array}{l}\text { Diastolic blood } \\
\text { pressure }(\mathrm{mmHg})\end{array}$ & $80 \cdot 5$ & $8 \cdot 7$ & $81 \cdot 1$ & $9 \cdot 4$ \\
\hline Heart rate (beats/min) & 70 & 10 & 69 & 10 \\
\hline $\begin{array}{l}\text { Daily cigarette smokers } \\
\text { (\% of patients) }\end{array}$ & \multicolumn{2}{|r|}{13} & \multicolumn{2}{|r|}{11} \\
\hline $\begin{array}{l}\text { Alcohol users } \\
\text { (\% of patients) }\end{array}$ & \multicolumn{2}{|r|}{32} & \multicolumn{2}{|c|}{30} \\
\hline
\end{tabular}

the 8-week intervention, and 80.1 (SD 8.6) $\mathrm{mmHg}$ at 4 weeks after the study for the active soya group. The corresponding results in the placebo group were 81.1 (SD 9.4) $\mathrm{mmHg}$ at screening, 81.3 (SD 9.7) $\mathrm{mmHg}$ after the 8-week intervention, and $80 \cdot 1$ (SD 9.9) $\mathrm{mmHg}$ at 4 weeks after the intervention.

\section{Body weight}

Body weight was measured in every single clinic visit for all patients. The groups were comparable at baseline, and there were no significant changes in mean weight throughout the duration of the study. Females in the active soya group had a slight mean change from 72.7 (SD 15.3) to 73.7 (SD 15.8) kg compared with a similarly negligent change from 68.7 (SD 12.8) to 69.6 (SD 12.9) $\mathrm{kg}$ in the placebo group. For males, the mean change was in the opposite direction, from 82.2 (SD 9.0) to 79.9 (SD $17 \cdot 8) \mathrm{kg}$ in the active soya group and from 84.5 (SD 10.8) to 82.6 (SD 18.9) $\mathrm{kg}$ in the placebo group.

\section{Discussion}

The present 8-week diet intervention trial in subjects with hypercholesterolaemia demonstrated that a product based on isolated soya protein with standardised levels of isoflavones, cotyledon soya fibres and soya phospholipids had modest, but clinically significant, lipid-lowering effects compared with a placebo. The findings confirm that in a population with mild-to-moderately elevated plasma lipids, effects on cholesterol lowering can be obtained with a functional food.

Law et al. (1994) have shown that for mild-to-moderate hypercholesterolaemic subjects, a $10 \%$ reduction in total cholesterol lowers the risk of cardiovascular events by up

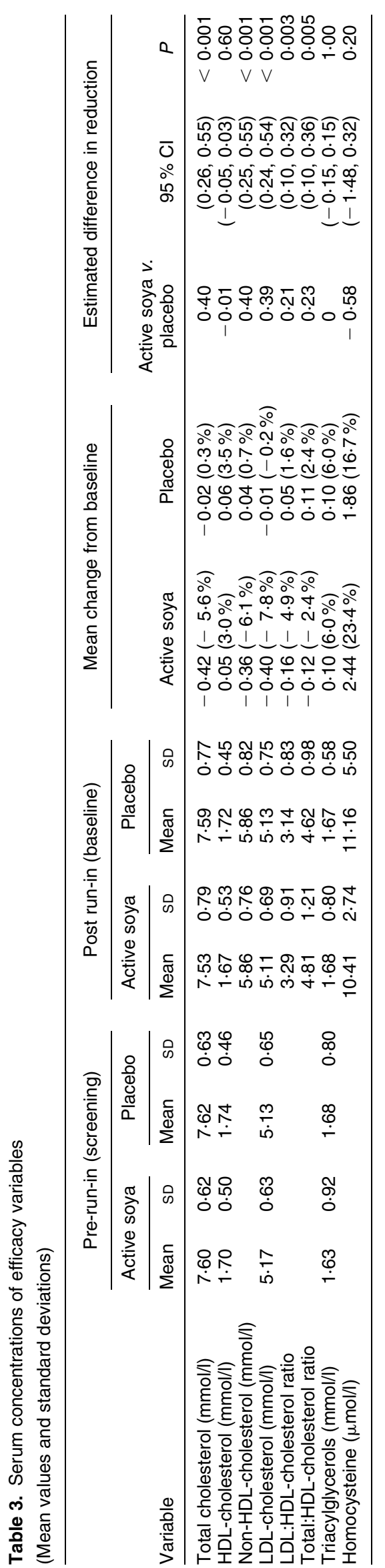




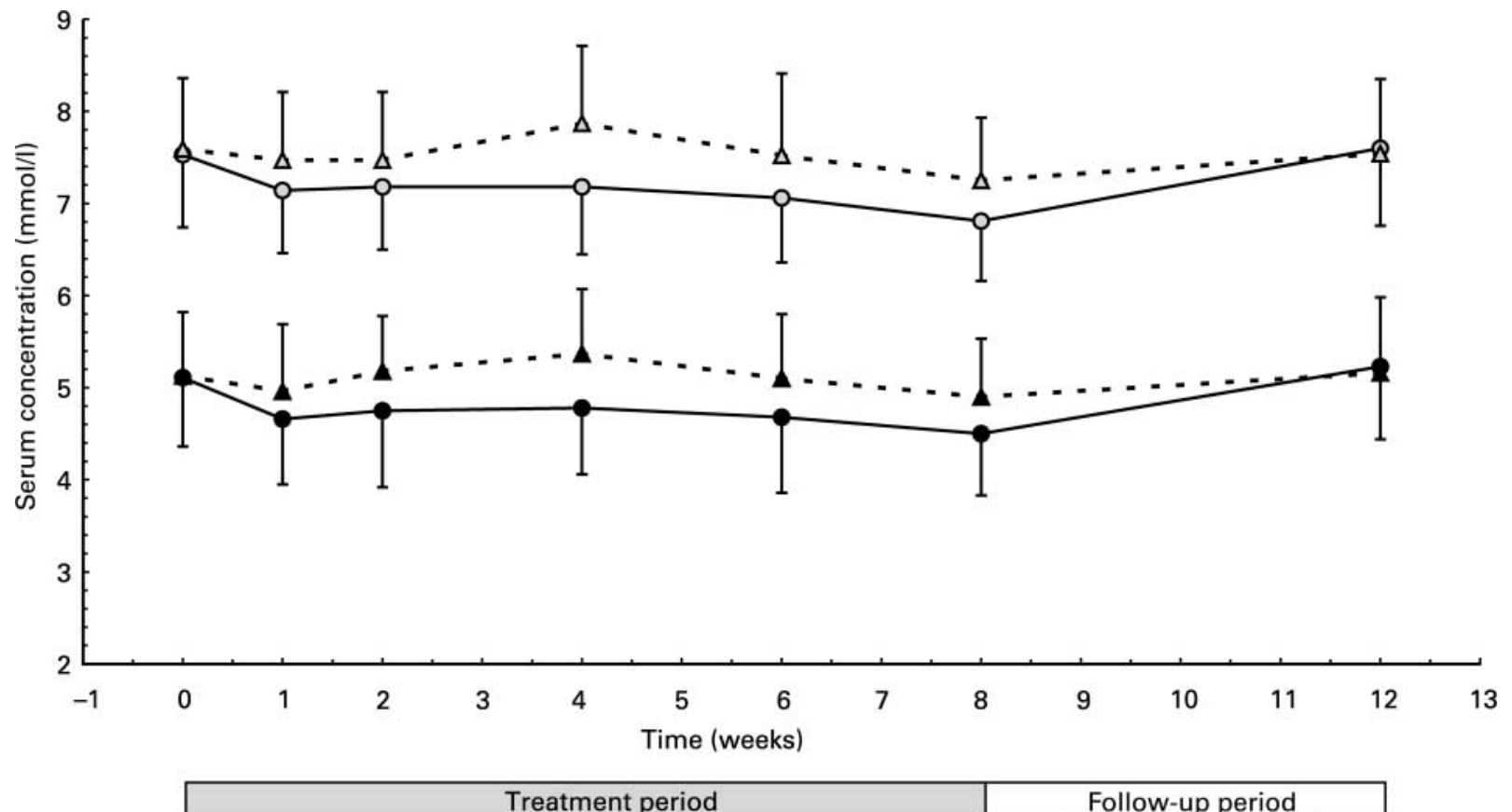

Fig. 2. Serum concentration $v$. time for total cholesterol in the active soya group (-○-), total cholesterol in the placebo group (- $-\Delta--)$, LDL-cholesterol in the active soya group (-๑-), and LDL-cholesterol in the placebo group (- - $\mathbf{\Delta -}-$ ). Mean values are shown, with standard deviations represented by vertical bars.

to $50 \%$ for a 40 -year-old individual, and gradually less for older subjects. However, extrapolating risk reduction based on cholesterol alone is probably much too crude. With regard to the risk of CHD, it is not known whether otherwise healthy subjects would benefit from taking soya fibre for several years; neither has long-term safety been studied carefully.

Despite the test product being a dietary supplement by classification, we designed and conducted the study according to the guidelines for developing medicinal products. We employed both general principles (International Conference on Harmonization topics E6, E8, E9, and E10; European Agency for the Evaluation of Medicinal Products, 1996, 1997, 1998, 2000) and specific ones for the treatment of dyslipoproteinaemia (European Agency for the Evaluation of Medicinal Products, 2001). It is well known, and comprehensively reviewed by Sandström (1995), that dietary supplement studies include a number of confounding factors, since such intake most often includes other dietary components as well. Seasonal or dietary adaptation, as well as inaccuracy of self-reporting of dietary data, further complicate the analysis. Strict dietary food control could have controlled changes of individual food intake. The study intended to diminish any effect on normal life settings. The effect of keeping a food diary could have introduced an adverse effect on normal life of these subjects compared with only frequent visits to the study nurse, and was considered inappropriate.

As the present study was an early proof-of-concept one, we aimed to include subjects with the highest probability of showing an effect, and thus we included subjects with as high lipid levels as possible. However, the subjects were not so hypercholesterolaemic that intervention with a statin or another licensed lipid-lowering drug would be mandatory according to public guidelines at the time of planning the study. The meta-analysis by Anderson et al. (1995) showed that sex does not affect the response to soya protein, but whether isoflavones could have lesser effects in women with premenopausal oestrogen levels was not addressed in their paper. Consequently, we chose not to include this patient group in the present study.

The placebo was a standard low-fat yoghurt available on the consumer market. Cherry jam was added to this yoghurt in order to make it similar to the soya yoghurt. The two products were not completely identical in fat content as there were manufacturing obstacles to maintain blinding in terms of appearance, smell and taste if the fat content should be kept identical. Obviously, this difference in fat content may explain some of the differences, and needs careful considerations in future studies. Whether this choice was truly a placebo is also questionable, as the placebo group also showed a mean reduction in lipids, and regression to the mean would also be one possible explanatory factor.

For the primary efficacy variable (LDL-cholesterol), there was a highly significant difference between the active soya treatment and the placebo corresponding to a mean reduction from baseline of $0.42 \mathrm{mmol} / \mathrm{l}$ (corresponding to a $7.8 \%$ difference in reduction) for the subjects taking active soya. Similar results, demonstrating a consistent beneficial effect, were also seen for total cholesterol and non-HDL-cholesterol, as well as for the LDL:HDL-cholesterol and total:HDL-cholesterol ratios. The present results suggest that the effect of soya protein and fibre are somewhat higher than seen in previously reported studies with the same duration of treatment (Anderson et al. 1995; Baum et al. 1998; Wong et al. 1998; Crouse et al. 1999; Merz-Demlow et al. 2000; Teixeira et al. 2000). 
The rapid onset of the cholesterol-lowering effect was striking, even if this phenomenon is well known from other dietary intervention studies. About half of the effect after 8 weeks was seen already after the first week of intervention. These early lipid changes could be due to weight loss, but upon inspection we were not able to explain our findings by the weight data. This rapid onset of effect may prove beneficial to patients who need motivation in the early phases of treatment, and in particular for those patients who are not able to comply with lifestyle modification programmes.

In recent years, homocysteine has been introduced as a potential risk factor for atherosclerosis (Boushey et al. 1995; Gerhard \& Duell, 1999; Wald et al. 2002). A previous study with Abacor $^{\circledR}$ in a ready-to-mix beverage form (Tonstad et al. 2002) had demonstrated favourable effects with a daily dose of $30-50 \mathrm{~g}$ soya protein, but the present results were not able to confirm this effect in the yoghurt formulation.

It has been shown that related products based on soya are efficient in reducing weight and maintaining the weight loss over time (Rössner \& Flaten, 1997; Ryttig et al. 1997). One could also have expected some weightreduction benefit from participating in the present study as the subjects were asked to follow a standardised healthy diet scheme. We expected that subjects who are followed carefully with bi-weekly weight measurements in a medical clinic by health professionals would be likely to adhere truthfully to the dietary programme and in general lose weight because of greater focus on and awareness of a healthy lifestyle. The present results did not demonstrate any significant weight reduction even if a slight tendency in the male groups was noted, but 8 weeks may be too short to see any effects.

The yoghurt formulation used in the present study was not well tolerated. Microbiological (mould) contamination in some of the soya yoghurt cups from one shipment partly explained the dropout problems in the active soya group. However, even when correcting for this, the number of dropouts and complaints due to gastrointestinal symptoms were higher in the active soya group. The high intake of fibre may partly explain the gastrointestinal symptoms reported by some subjects. The usability of this prototype product is also limited in practice because of the relatively large volume of yoghurt, almost $300 \mathrm{ml}$ twice daily. Whether the difference in yoghurt composition (energy or fatty acids or fermenting organism) influenced the results should be studied in later product development and clinical investigations. A lower dose taken for a longer term might be as or even more efficient but this remains to be confirmed in further dose-response investigations. Except for the gastrointestinal symptoms, both study groups showed a similar tolerability profile and the study did not indicate any particular safety concerns. However, the present study was not designed to address the safety issue specifically, and larger therapeutic use studies or post-marketing surveillance must be undertaken in order to shed more light on this aspect.

In conclusion, the present study supports a significant lipid-lowering effect of isolated soya proteins with standardised levels of isoflavones, cotyledon soya fibres and soya phospholipids. Some product development is recommended in order to avoid the gastrointestinal symptoms, and to reduce the volume to be ingested. Dependent on evidence from confirmatory and long-term trials, this soya yoghurt might then be a first intervention step in hypercholesterolaemia in addition to general dietary changes and possibly as an add-on to statin therapy. The rapid onset of effect may prove particularly beneficial to patients who need motivation in the early phases of intervention.

\section{Acknowledgements}

We would like to acknowledge the dedicated assistance by Pertti Puhakka (sub-investigator), Liisa Purmonen (study nurse), Timo Lahti, Merja Sariola and Irene Wassdal Fuglem (monitoring), Arne Huseb $\varnothing$ (data management), and Joerg Gruenwald, Eve Morgenstern and Bo Dinesen (comments on the manuscript). The study products were provided by The Agricultural University of Norway, Ås, Norway. Nutri Pharma ASA, Oslo, Norway supported the study financially.

\section{References}

Adlercreutz H (1998) Epidemiology of phytoestrogens. Ballières Clin Endocrinol Metab 12, 605-623.

Anderson JW (2003) Diet first, then medication for hypercholesterolemia. J Am Med Assoc 290, 531-533.

Anderson JW, Johnstone BM \& Cook-Newell ME (1995) Metaanalysis of the effects of soy protein intake on serum lipids. $N$ Engl J Med 333, 276-282.

Anderson JW, Smith BM \& Washnock CS (1999) Cardiovascular and renal benefits of dry bean and soybean intake. Am J Clin Nutr 70, Suppl., 464S-474S.

Anonymous (1998) Joint British recommendations on prevention of coronary heart disease in clinical practice. British Cardiac Society, British Hyperlipidaemia Association, British Hypertension Society, endorsed by the British Diabetic Association. Heart 80, Suppl. 2, 1S-29S.

Anonymous (2002) Third Report of the National Cholesterol Education Program (NCEP). Expert Panel on Detection, Evaluation and Treatment of High Blood Cholesterol in Adults (Adult Treatment Panel III final report). Circulation 106, 3143-3421.

Avorn J, Monette J, Lacour A, Bohn RL, Mogun H \& LeLorier J (1998) Persistence of use of lipid-lowering medications: a cross-national study. J Am Med Assoc 279, 1458-1462.

Baum JA, Teng H, Erdman JW Jr, et al. (1998) Long-term intake of soy protein improves blood lipid profiles and increases mononuclear cell low-density-lipoprotein receptor messenger RNA in hypercholesterolemic, postmenopausal women. Am J Clin Nutr 68, 545-551.

Boushey CJ, Beresford SA, Omenn GS \& Motulsky AG (1995) A quantitative assessment of plasma homocysteine as a risk factor for vascular disease. Probable benefits of increasing folic acid intakes. JAMA 274, 1049-1057.

Crouse JR III, Morgan T, Terry JG, Ellis J, Vitolins M \& Burke GL (1999) A randomized trial comparing the effect of casein with that of soy protein containing varying amounts of isoflavones of plasma concentrations of lipids and lipoproteins. Arch Intern Med 159, 2070-2076.

European Agency for the Evaluation of Medicinal Products (1996) ICH Topic E6: Note for Guidance on Good Clinical 
Practice, CPMP/ICH/135/95. London: European Agency for the Evaluation of Medicinal Products.

European Agency for the Evaluation of Medicinal Products (1997) ICH Topic E8: Note for Guidance on General Considerations for Clinical Trials, CPMP/ICH/291/95. London: European Agency for the Evaluation of Medicinal Products.

European Agency for the Evaluation of Medicinal Products (1998) ICH Topic E9: Note for Guidance on Statistical Principles for Clinical Trials, CPMP/ICH/363/96. London: European Agency for the Evaluation of Medicinal Products.

European Agency for the Evaluation of Medicinal Products (2000) ICH Topic E10: Note for Guidance on Choice of Control Groups in Clinical Trials, CPMP/ICH/364/96. London: European Agency for the Evaluation of Medicinal Products.

European Agency for the Evaluation of Medicinal Products (2001) Concept Paper on the Development of a Committee for Proprietary Medicinal Products (CPMP) Note for Guidance on the Evaluation of Medicinal Products for the Treatment of Dyslipoproteinaemia, CPMP/EWP/512/01. London: European Agency for the Evaluation of Medicinal Products.

Friedewald WT, Levy RI \& Fredrickson DS (1972) Estimation of the concentration of low-density lipoprotein cholesterol in plasma, without use of the preparative ultracentrifuge. Clin Chem 18, 499-502.

Gerhard GT \& Duell PB (1999) Homocysteine and atherosclerosis. Curr Opin Lipidol 10, 417-428.

Grundy SM (2000) Early detection of high cholesterol levels in young adults. $J$ Am Med Assoc 284, 865-867.

Heart Protection Study Collaborative Group (2002) MRC/BHF Heart Protection Study of cholesterol lowering with simvastatin in 20536 high-risk individuals: a randomised placebo-controlled trial. Lancet 360, 7-22.

Hsia SL, He JL, Nie Y, Fong K \& Milikowski C (1996) The hypocholesterolemic and antiatherogenic effects of topically applied phosphatidylcholine in rabbits with heritable hypercholesterolemia. Artery 22, 1-23.

Ishida T, Koba K, Sugano M, Imaizumi K, Watanabe S \& Minoshima RM (1988) Cholesterol levels and eicosanoid production in rats fed phosphatidylinositol or soybean lecithin. J Nutr Sci Vitaminol 34, 237-244.

Law MR, Wald NJ \& Thompson SG (1994) By how much and how quickly does reduction in serum cholesterol concentration lower risk of ischaemic heart disease? BMJ 308, 367-372.

LeBlanc MJ, Gavino V, Perea A, Yousef IM, Lévy E \& Tuchweber B (1998) The role of dietary choline in the beneficial effects of lecithin on the secretion of biliary lipids in rats. Biochim Biophys Acta 1393, 223-234.

Lovati MR, Manzoni C, Gianazza E, Arnoldi A, Kurowska E, Carroll KK \& Sirtori CR (2000) Soy protein peptides regulate cholesterol homeostasis in Hep G2 cells. $J$ Nutr 130, 2543-2549.

Merz-Demlow BE, Duncan AM, Wangen KE, Xu X, Carr TP, Phipps WR \& Kurzer MS (2000) Soy isoflavones improve plasma lipids in normocholesterolemic, premenopausal women. Am J Clin Nutr 71, 1462-1469.

Monkman D (2000) Treating dyslipidaemia in primary care (editorial comment). BMJ 321, 1299-1300.

Navder KP, Baraona E \& Lieber CS (2000) Dilinoleoylphosphatidylcholine protects human low density lipoproteins against oxidation. Atherosclerosis 152, 89-95.

Nishina PM \& Freedland RA (1990) The effects of dietary fiber feeding on cholesterol metabolism in rats. J Nutr 120, 800-805.

Pietinen P, Vartiainen E, Seppänen R, Aro A \& Puska P (1996) Changes in diet in Finland from 1972 to 1992: impact on coronary heart disease risk. Prev Med 25, 243-250.

Polichetti E, Diaconescu N, de la Porte PL, Malli L, Portugal H, Pauli AM, Lafont H, Tuchweber B, Yousef I \& Chanussot F
(1996) Cholesterol-lowering effect of soyabean lecithin in normolipidaemic rats by stimulation of biliary lipid secretion. Br J Nutr 75, 471-481.

Polichetti E, Janisson A, de la Porte PL, Portugal H, Léonardi J, Luna A, La Droitte P \& Chanussot F (2000) Dietary polyenylphosphatidylcholine decreases cholesterolemia in hypercholesterolemic rabbits: role of the hepato-biliary axis. Life Sci 67, 2563-2576.

Potter SM (1998) Soy proteins and cardiovascular disease: the impact of bioactive components in soy. Nutr Rev 56, 231-235.

Primatesta P \& Poulter NR (2000) Lipid concentrations and the use of lipid lowering drugs: evidence from a national cross sectional survey. BMJ 321, 1322-1325.

Puska P, Korpelainen V, Høie LH, Skovlund E, Lahti T \& Smerud K (2002) Soy in hypercholesterolemia: a doubleblind, placebo-controlled trial. Eur J Clin Nutr 56, 352-357.

Rosseneu M, Declercq B, Vandamme D, Vercaemst R, Soetewey F, Peeters H \& Blaton V (1979) Influence of oral polyunsaturated and saturated phospholipid treatment on the lipid composition and fatty acid profile of chimpanzee lipoproteins. Atherosclerosis 32, 141-153.

Rössner S \& Flaten H (1997) VLCD versus LCD in long-term treatment of obesity. Int J Obes Relat Metab Disord 21, $22-26$.

Ryttig KR, Flaten H \& Rössner S (1997) Long-term effects of a very low calorie diet (Nutrilett) in obesity treatment. A prospective, randomized, comparison between VLCD and a hypocaloric diet + behaviour modification and their combination. Int J Obes Relat Metab Disord 21, 574-579.

Sandström B (1995) Quality criteria in human experimental nutrition research. Eur J Clin Nutr 49, 315-322.

Shepherd J, Cobbe SM, Ford I, Isles CG, Lorimer AR, MacFarlane PW, McKillop JH \& Packard CJ (1995) Prevention of coronary heart disease with pravastatin in men with hypercholesterolemia. West of Scotland Coronary Prevention Study Group. N Engl J Med 333, 1301-1307.

Stamler J, Daviglus ML, Garside DB, Dyer AR, Greenland P \& Neaton JD (2000) Relationship of baseline serum cholesterol levels in 3 large cohorts of younger men to long-term coronary, cardiovascular, and all-cause mortality and to longevity. $J \mathrm{Am}$ Med Assoc 284, 311-318.

Teixeira SR, Potter SM, Weigel R, Hannum S, Erdman JW Jr \& Hasler CM (2000) Effects of feeding 4 levels of soy protein for 3 and 6 weeks on blood lipids and apolipoproteins in moderately hypercholesterolemic men. Am J Clin Nutr 71, 1077-1084.

The Long Term Intervention with Pravastatin in Ischaemic Disease (LIPID) Study Group (1998) Prevention of cardiovascular events and death with pravastatin in patients with coronary heart disease and a broad range of initial cholesterol levels. N Engl J Med 339, 1349-1357.

The Scandinavian Simvastatin Survival Study Group (1994) Randomised trial of cholesterol lowering in 4444 patients with coronary heart disease: the Scandinavian Simvastatin Survival Study (4S). Lancet 344, 1383-1389.

The Swedish Medical Product Agency and the Norwegian Medicines Control Authority (1996) Workshop: Treatment of Hyperlipidaemia. 1996-1992. Stockholm: The Swedish Medical Product Agency and the Norwegian Medicines Control Authority.

Tonstad S, Smerud K \& Høie L (2002) A comparison of the effects of 2 doses of soy protein or casein on serum lipids, serum lipoproteins, and plasma total homocysteine in hypercholesterolemic subjects. Am J Clin Nutr 76, 78-84.

US Food and Drug Administration (1999) Food labeling: health claims; soy protein and coronary heart disease. Federal register: 
October 26, 1999 (Volume 64, Number 206) Rules and regulations: 21 CFR part 101 (Docket no. 98P-0683): 57699-731. www.wais.access.gpo.gov

Vartiainen E, Puska P, Pekkanen J, Tuomilehto \& Jousilahti P (1994) Changes in risk factors explain changes in mortality from ischaemic heart disease in Finland. BMJ 309, 23-27.

Wald DS, Law M \& Morris JK (2002) Homocysteine and cardiovascular disease: evidence on causality from a meta-analysis. BMJ 325, 1202-1206.
Wang GJ, Lapcik O, Hampl R, Uehara M, Al-Maharik N, Stumpf K, Mikola H, Wahala K \& Adlercreutz H (2000) Time-resolved fluoroimmunoassay of plasma daidzein and genistein. Steroids 65, 339-348.

Wong WW, O'Brian Smith E, Stuff JE, Hachey DL, Heird WC \& Pownell HJ (1998) Cholesterol-lowering effect of soy protein in normocholesterolemic and hypercholesterolemic men. Am J Clin Nutr 68, Suppl., 1385S-1389S. 